J. Dairy Sci. 87:2846-2853

(c) American Dairy Science Association, 2004.

\section{Towards an Optimum Mixing Protocol for On-Farm Bulk Milk Sampling}

\author{
V. Servello, A. R. Hill, and R. W. Lencki \\ Department of Food Science, \\ University of Guelph, Ontario, Canada N1G 2W1
}

\begin{abstract}
This paper describes the application of a bottom-sampling technique to dynamically monitor creaming and mixing in bulk milk tanks and determine optimum mixing protocols for milk sampling. Creaming onset in field experiments occurred between 40 and $50 \mathrm{~min}$. Bottomsampling data determined after $3 \mathrm{~h}$ of creaming indicate that the mean mixing time required to ensure a homogenous sample for composition testing is $57 \mathrm{~s}$, and there is a less than $1 \%$ probability that an individual tank would require more than 2 min of agitation. Bottom and top-sampling statistics determined after $1 \mathrm{~h}$ of creaming indicate mean mixing times of 20 and $34 \mathrm{~s}$, respectively, and predict that individual tank mixing times will exceed 46 and $64 \mathrm{~s}$, respectively, less than $1 \%$ of the time. Bacterial cell counts were directly correlated with fat content, but somatic cell counts were independent of fat content. Based on these results, it is recommended that hourly agitation of bulk tanks as currently prescribed in many jurisdictions should be maintained, but the duration of intermittent agitation should be reduced from 5 to 2 min to reduce the impact of agitation on fat globule stability. If hourly agitation is effected during milk storage, agitation time before sampling can be reduced from 5 to $2 \mathrm{~min}$. This will save time for drivers and trucks and reduce the potential impact of agitation on fat globule stability.
\end{abstract}

(Key words: milk sampling, creaming, agitation time)

Abbreviation key: DFO = Dairy Farmers of Ontario, Mississauga, Ontario, QC = quality control, UHT = ultra high temperature, LSD = Lab Services Division, University of Guelph.

\section{INTRODUCTION}

Creaming of quiescent raw milk leads to stratification of the milk fat globules. Bacteria can also accumulate at the surface of raw milk because they often associate

Received November 26, 2003.

Accepted April 19, 2004

Corresponding author: A. R. Hill; e-mail: arhill@uoguelph.ca. with the rising fat globules (Belknap, 1978). Consequently, adequate mixing is essential in order to obtain a representative analysis sample from farm bulk milk tanks. A previous examination of the literature on bulk milk tank mixing has indicated that it is generally agreed that at least 5 min of mixing-and perhaps up to $10 \mathrm{~min}$ with very large bulk tanks-is required to obtain homogeneity (Goodridge et al., 2004). Having milk tank truck drivers wait this length of time at every pick-up would be an inefficient use of personnel time and equipment. This problem has been circumvented in several ways: Some jurisdictions, like the province of Quebec in Canada, have outfitted their milk trucks with autosamplers (Beauséjour, 1992), but it is unclear whether this approach is cost effective. New Zealand has decided to continuously stir all their milk tanks, and this has been shown to maintain homogeneity even with tanks up to $30,000 \mathrm{~L}$ (Goodridge et al., 2004). However, excessive stirring can lead to churning and reduced milk quality (Walstra, 1983), so it is unclear whether continuous stirring would lead to problems with fat globule stability.

Many regulatory bodies, such as the Province of Ontario (where this study took place) (OMAF, 1983), and the IDF (IDF, 1995), have implemented the use of intermittent mixing as a means of reducing the mixing time required to obtain a representative sample from farm bulk milk tanks. However, a survey of international standards (Goodridge et al., 2004) has shown that rarely is a specific intermittent protocol specified. In addition, it would appear that no studies have examined how intermittent mixing would affect the time required to reach homogeneity within a farm bulk milk tank.

The purpose of this work was to determine optimal mixing protocols for milk sampling from on-farm bulk tanks for milk composition and quality analysis. To obtain enough experimental points for the statistical analysis first required the development of a means of rapidly sampling bulk milk tanks. With this sampling methodology in place, creaming phenomena and subsequent mixing behavior was examined to determine how intermittent agitation affects bulk tank mixing time. 


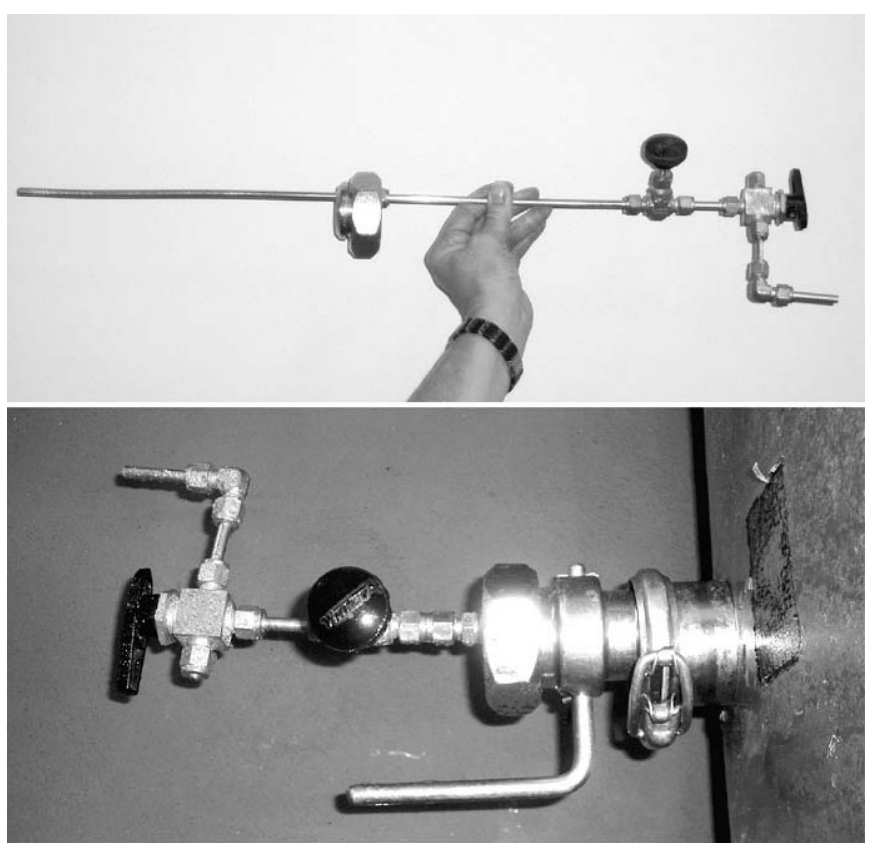

Figure 1. Bottom-sampling device capable of taking 30-mL samples at 10 -s intervals. The top view shows the entire device disengaged from the tank; the bottom view shows the sampling device installed in a bulk tank.

\section{MATERIALS AND METHODS}

\section{Milk Tank Sampling Procedures}

Top-sampling from bulk tanks was accomplished using a $10-\mathrm{mL}$ capacity straw as prescribed by Ontario Regulations (DFO, 2001). The straw was dipped into the milk tank 3 times to obtain the $30 \mathrm{~mL}$ of total liquid required for proper analysis. This procedure required a minimum of $20 \mathrm{~s}$ to complete and preliminary experiments demonstrated that this was too slow to obtain sufficient samples to define an accurate mixing curve for bulk tank milk. Further, preliminary bench-scale experiments demonstrated that it was very difficult to obtain reproducible results by top-sampling the cream layer of quiescent raw milk (results not shown). The fat concentration obtained was highly dependent on the depth at which the sample was taken and how quickly the sample was drawn into the $10-\mathrm{mL}$ sampling straw. Therefore, it was concluded that top sampling was inadequate for both creaming and mixing experiments. Consequently, a bottom-sampling device was designed to increase the milk sampling rate (Figure 1).

A $1 / 4^{\prime \prime}$-outside diameter, 24"-long 304 stainless steel tube was mounted onto a threaded standard 2 " tank outlet pipe cap using a Swagelok compression fitting fitted with a polyethylene ferrule. The compression fitting was threaded onto the pipe cap at an off-center position so that the tube could be pushed past the open butterfly valve on the tank outlet just upstream from the pipe cap. A needle valve was used to control the milk flow rate and a 3-way valve was fitted onto the end of the tube to control the flow through 2 outlets-one for collecting samples and one to act as a bypass. The sampling device with the tube retracted close to the cap could then be screwed onto a bulk tank filled with milk and the outlet butterfly valve was closed. Once the device was fitted into place, the outlet butterfly valve could be opened, and, with the compression fitting slightly loosened, the tube could be pushed past the valve and $12^{\prime \prime}$ into the tank bottom. After tightening the compression fitting, the device was ready for sampling.

For each experiment, the flow rate was set so that a $30-\mathrm{mL}$ sample bottle could be filled in roughly $4 \mathrm{~s}$; thus, it was possible to take a $30-\mathrm{mL}$ sample at 10 -s intervals. Another advantage of this device is that the samples were taken from the bottom of the tank, the region that would most likely be first affected by creaming and the last to reach homogeneity once mixing was initiated. Therefore, from a lack of homogeneity perspective, we were always looking at the worst-case scenario.

\section{Milk Bulk Tank Survey}

Bulk tank variables such as size, shape, \% fill, and temperature at the time of milk pick-up, as well as the shape and rotation speed of the agitator would likely affect mixing behavior. Thus, it seemed prudent to conduct a survey of bulk tank characteristics that included the tank manufacturer, capacity, percent fill, and milk temperature. This was accomplished using records provided by the DFO. Statistical summaries and, where appropriate, histograms, of the data were prepared to assess the range of characteristics relevant to mixing. In addition, 34 farms were visited to view impeller configuration, and agitation flow patterns. Length, width, and height measurements were taken to assess variations in tank size and shape.

Considering the diversity of bulk tank characteristics relevant to mixing time, it seemed obvious that a rigorous experimental design would require mixing time determinations for an impractically large number of tanks. We approached the problem in 2 ways: First, we determined mixing times for tanks with a wide range of characteristics after $3 \mathrm{~h}$ of creaming. The rationale for this experiment was that if we could demonstrate similar mixing curves for tanks with widely differing characteristics, then it would be reasonable to assume that these results could be applied to all tanks. Next, we selected 5 tanks with widely varying characteristics and tested them repeatedly (5 times) to estimate mixing times after only $1 \mathrm{~h}$ of creaming to evaluate the repeat- 
Table 1. Characteristics of the 5 tanks chosen for detailed creaming and mixing time experiments. All tanks were in excess of $75 \%$ of capacity when the tests were completed.

\begin{tabular}{lllll}
\hline $\begin{array}{l}\text { Tank } \\
\#\end{array}$ & Manufacturer & $\begin{array}{l}\text { Capacity } \\
(\mathrm{L})\end{array}$ & Shape & $\begin{array}{l}\text { Dimensions } \\
\text { L/W/H }\end{array}$ \\
\hline 1 & DeLaval & 1500 & Square & $2.33 / 1.52 / 0.76$ \\
2 & Kraft & 1700 & Square & $3.34 / 1.24 / 0.89$ \\
3 & Mueller & 1134 & Half-elliptical & $2.35 / 1.30 / 0.75$ \\
4 & Mueller & 2460 & Elliptical & $2.34 / 1.54 / 1.09$ \\
5 & Mueller & 2500 & Elliptical & $2.34 / 1.53 / 1.13$ \\
\hline
\end{tabular}

ability of mixing time determinations (Table 1 summarizes the characteristics of the 5 selected tanks). This experiment included simultaneous bottom and topsampling to confirm that the results from the new bottom-sampling method could be correlated to the standard top-sampling technique as prescribed by the Ontario Milk Act (OMAF, 1983).

\section{Creaming Experiments}

The creaming rate of raw milk was assessed for 2 elliptical and 2 square bulk tanks. In all cases, the tank percentage fill was $>70 \%$. After the milk from the morning milking was cooled to $<4^{\circ} \mathrm{C}$, the agitator was turned off and bottom samples were taken at 10-min intervals for a period of $3 \mathrm{~h}$. To factor out the effect of batch-to-batch and farm-to-farm milk variation, normalized fat content (i.e., $\%$ fat $/ \%$ fat $_{t=0}$ ) was plotted as a function of time.

\section{Mixing Time Experiments}

Bottom-sampling. The bottom-sampling device was used to develop mixing curves for 26 different tanks. The tanks were chosen based on the initial bulk tank survey and included square, round, elliptical, and semielliptical shapes, sizes in the range of 3000 to 30,000 $\mathrm{L}$, and 40 to $100 \%$ fill. It was necessary to select only tanks that were scheduled for afternoon pick-up to allow enough time to conduct the experiments. After the morning milking, the milk was fully cooled with agitation to $4^{\circ} \mathrm{C}$, and then allowed to cream under quiescent conditions for $3 \mathrm{~h}$. At that time, the bottom-sampling device was secured to the vat, the agitator was turned on, and samples were taken at 30 -s intervals for the first $3 \mathrm{~min}$ and then every $60 \mathrm{~s}$ for an additional 4 min.

Top vs. bottom-sampling. Two square tanks, 2 elliptical tanks, and 1 semi-elliptical tank were selected for further mixing experiments (Table 1). The fill level in all 5 tanks was greater than $70 \%$ of capacity. Following the morning milking, the milk was chilled to $4^{\circ} \mathrm{C}$ and then allowed to rest for $60 \mathrm{~min}$ before commencement of mixing experiments. During agitation, top- and bottomsamples were taken at intervals of 30 and $10 \mathrm{~s}$, respectively. The longer interval for top-sampling was necessary to allow time for manual sampling. The bottomsampling device was cleaned and sanitized between tanks, but could not be considered sterile at the beginning of each experiment. Samples were tested for composition using a MilkoScan 4000 (Foss Analytical, Hillerod, Denmark), and total bacterial counts using a BactoScan 8000S (Foss Analytical) at Laboratory Services Division, University of Guelph.

The experiment was replicated 5 times, so the design can be summarized as a factorial experiment with 5 experimental units (individual farm bulk tanks), a class variable with 3 levels (3 tank shapes), a second class variable with 2 levels (bottom versus top-sampling), 3 quantitative response variables (milk fat content, bacteria counts, and SCC) and 5 replicates. Normalized percentage wt/wt fat values and bacterial counts were plotted vs. agitation time.

\section{Statistics}

Unless otherwise noted in Results and Discussion, all data were analyzed by SAS general linear model and means procedures (SAS Institute, 2000). Statistical significance was indicated by $P<0.05$.

\section{RESULTS AND DISCUSSION}

\section{Tank Characteristics}

A few older square-shaped tanks are still in use, but most modern bulk tanks have a circular or elliptical vertical cross section. The 4 most common makers of tanks owned by Ontario farmers, namely, Mueller (Springfield, MO), DeLaval (Peterbourough, ON), Westfalia Surge (Naperville, IL), and Bou-Matic Darikool (Madison, WI) represented 41, 27, 12, and 9\% of the tanks, respectively. Tank models were matched with manufacturer specifications to assess shape characteristics. Width-to-height ratios ranged from 1.0 to 1.2, and length-to-width ratios ranged from 1.0 to 2.5 . The length-to-width ratio is strongly associated with tank size but the shape (width by height) is relatively constant. Table 2 is a means table of tank capacity, volume shipped, percent fill and temperature at the time of pick up for 6313 bulk tanks. The fact that the maximum $\%$ fill is $>100 \%$ in some cases is probably because some tanks have been replaced with larger tanks so the volume shipped has increased, but the tank capacities in the database are not all up-to-date. Nevertheless, the data is helpful to illustrate the variation of several variables likely to affect mixing times. The farm tour identified other potential variables. Impellers varied greatly 
Table 2. Summary of Ontario bulk tank characteristics. ${ }^{1}$

\begin{tabular}{lrrrr}
\hline & $\begin{array}{l}\text { Tank } \\
\text { capacity } \\
(\mathrm{L})\end{array}$ & $\begin{array}{l}\text { Volume } \\
\text { shipped } \\
(\mathrm{L})\end{array}$ & $\begin{array}{l}\text { Temperature } \\
\left({ }^{\circ} \mathrm{C}\right)\end{array}$ & \% Fill \\
\hline Average & 3180 & 2083 & 3.7 & 66 \\
Mode & 3066 & 951 & 3 & 100 \\
Maximum & 30,358 & 19,569 & 12 & 202 \\
Minimum & 606 & 158 & 1 & 5 \\
Standard deviation & 2018 & 1471 & 1.3 & 19 \\
Median & 2482 & 1737 & 3.4 & 65 \\
\hline
\end{tabular}

${ }^{1}$ Data provided by the DFO. $\mathrm{N}=6313$.

with respect to shape, position in the tank (off-centred or not) and rotation speed. Rotation speeds for the 34 tanks ranged from 23 to 40, but the vast majority were close to the average of $35 \mathrm{rpm}$. The distance of the agitator from the tank outlet ranged from 36 to $175 \mathrm{~cm}$, with an average of $108 \mathrm{~cm}$. It was obvious from casual observation that different impellers (flat-blade turbine versus angled-blade marine) produced different flow patterns during mixing.

Single temperature records for 6313 bulk tanks were obtained for August, November, February, and May during 1999/2000. Mean temperatures were 3.69, 3.63, 3.69 , and $3.63^{\circ} \mathrm{C}$, respectively, and the corresponding standard deviation values were $1.39,1.33,1.28$, and 1.33. ANOVA analysis did not indicate significant seasonal differences. The temperature frequency distributions (see the distribution for August 1999 in Figure 2)

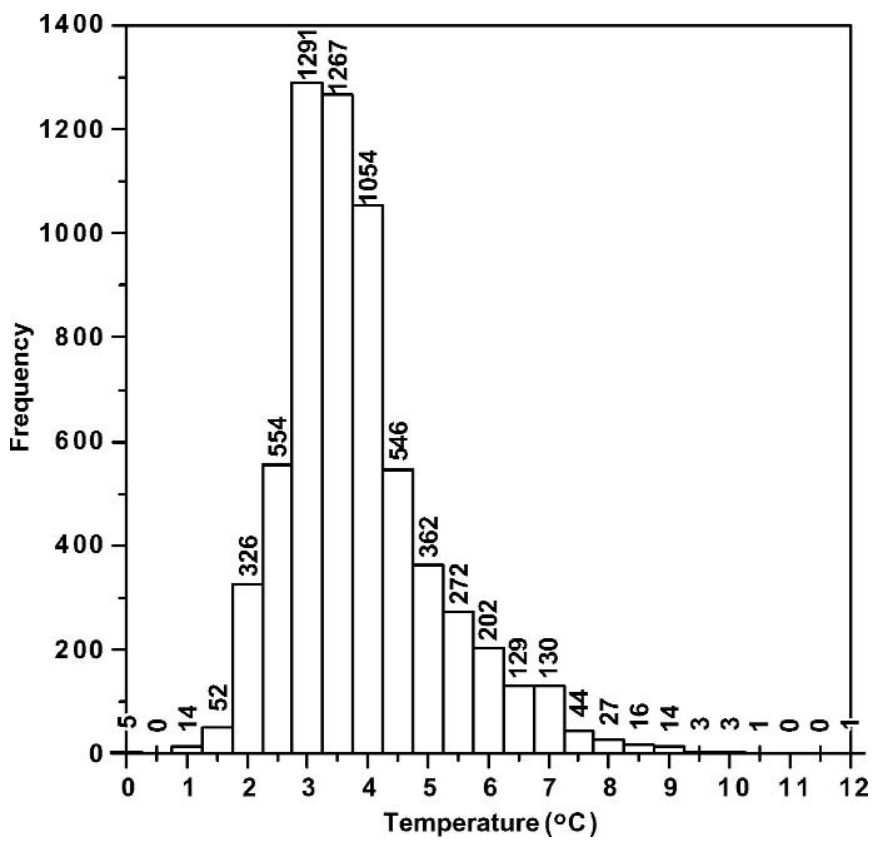

Figure 2. Frequency distribution of milk temperature at the time of milk pick up at Ontario farms. The data includes one measurement from each of 6313 tanks taken during August 1999.

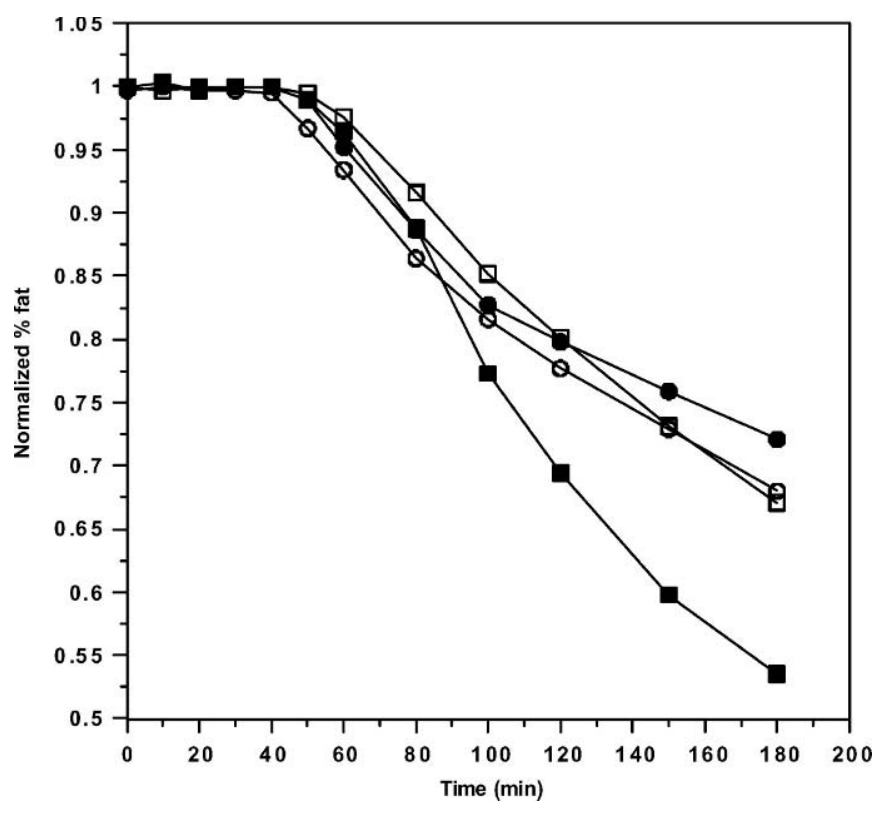

Figure 3. Normalized fat values versus time during creaming at $4^{\circ} \mathrm{C}$ for 2 elliptical (A - $\bigcirc$ and B - $)$ and 2 square tanks $(\mathrm{C}-\square$ and D - D). Normalized fat values are decimal fractions of the fat content of the same milks after thorough mixing.

show that about $25 \%$ of the bulk tanks had temperatures greater than the prescribed $4.0^{\circ} \mathrm{C}$. This data highlights the need to monitor compliance with milk cooling, storage, and sampling protocols in farm bulk milk tanks.

Temperature is a concern because of its large influence on the microbial quality of raw milk. However, milk temperature also affects the rate of creaming and the depth of the cream layer (Hammer, 1916; Ma and Barbano, 2000), so it may also have a significant effect on mixing time. Furthermore, temperature effects on fat globule instability (churning) are direct and significant within the range of 0 to $18^{\circ} \mathrm{C}$ (Walstra, 1983). Therefore, both temperature and agitation time are important to milk quality and yield factors such as free fat.

\section{Creaming Rates}

Gravity creaming behavior of milk is well documented (Dahlberg and Marquardt, 1931; Dunkley and Summer, 1944; Ma and Barbano, 2000). In Figure 3, normalized percentage wt/wt fat values for 2 elliptical and 2 square tanks are plotted versus time. The onset of measurable creaming occurred at 40 to $50 \mathrm{~min}$. Average fat depletion at the bottom of the tank was still only $30 \%$ (mean normalized fat $=0.699$ ) after $3 \mathrm{~h}$ of creaming. However, the standard deviation of the percentage wt/wt fat increased as the experiment progressed, indicating that the final amount of fat that 


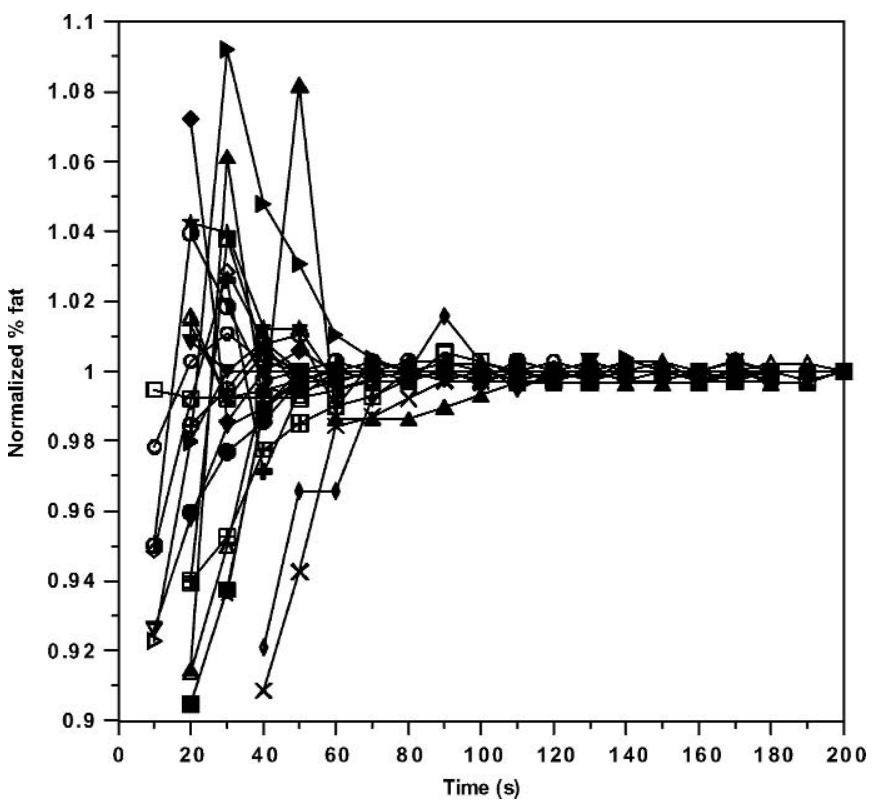

Figure 4. Normalized fat values versus time during mixing following $3 \mathrm{~h}$ of creaming for 26 tanks including a wide range of sizes, shapes, and fill levels. Normalized fat values are decimal fractions of the fat content of the same milks after thorough mixing. For context, the analytical repeatability associated with the fat analysis used in this experiment is $\pm 0.005 \%$, wt/wt.

creamed was quite variable. According to Walstra et al. (1999), cream layer thickness reaches a maximum after $4 \mathrm{~h}$ of quiescence. Our results are comparable to those of Jackson (1981), who observed the onset of creaming after approximately $30 \mathrm{~min}$. However, he also observed that the fat depletion at the bottom of the tank was close to $60 \%$ after standing $1.5 \mathrm{~h}$. Nevertheless, the average normalized fat value after 60 min of creaming was $0.957 \pm 0.016$. Therefore, hourly intermittent agitation should prevent substantial creaming during milk storage.

\section{Bottom-Sampling}

Mixing curves (normalized fat content versus agitation time) for 26 tanks after $3 \mathrm{~h}$ of creaming are presented in Figure 4. All curves appear to stabilize (flatten) in less than $110 \mathrm{~s}$, so based on casual review of these graphs, 2 min of agitation appears adequate before sampling for composition testing. To provide further perspective, consider that the International Association of Food Protection defines adequate agitation as that degree of agitation which, at full tank capacity, results in a variation in fat content of the milk in the tank of not more than $\pm 0.1 \% \mathrm{wt} / \mathrm{wt}$ as determined by an official AOAC milk fat test (IAFP, 1994). Thus, a plot of the absolute value of the difference between the

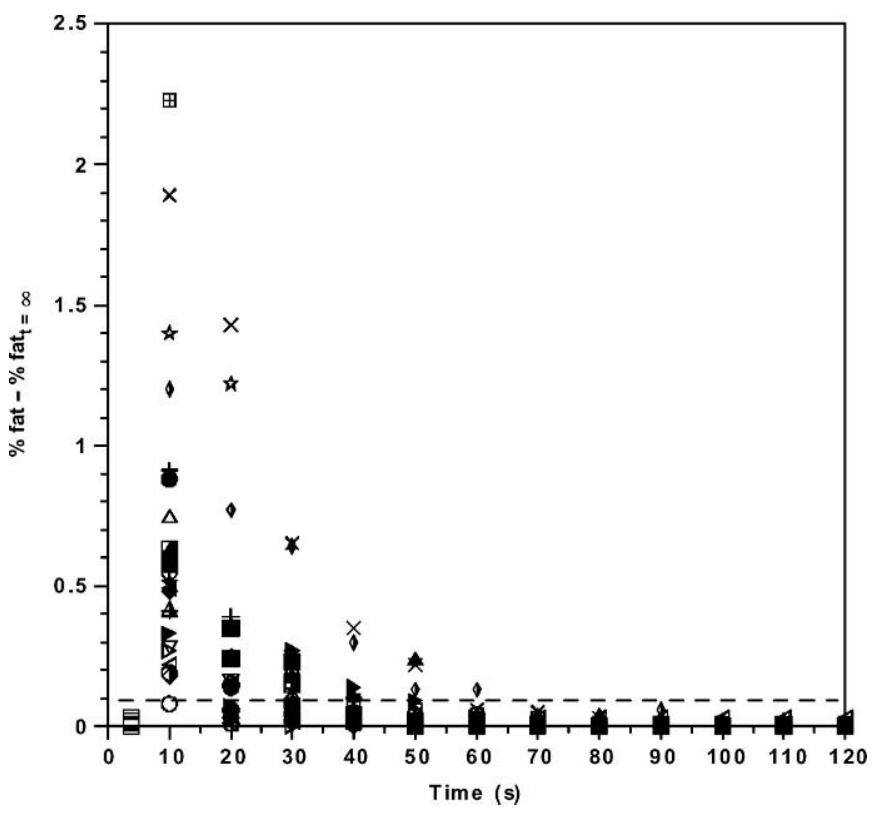

Figure 5. The absolute value of the difference between the \% wt/ wt fat at a particular time during mixing following $3 \mathrm{~h}$ of creaming and the plateau value of $\% \mathrm{wt} / \mathrm{wt}$ fat at extended mixing for 26 tanks.

percentage wt/wt fat at a particular time and the final plateau percentage $\mathrm{wt} / \mathrm{wt}$ fat at extended mixing time would provide a means of plotting error as a function of time (Figure 5). All tanks examined were within this $\pm 0.1 \% \mathrm{wt} / \mathrm{wt}$ limit within $70 \mathrm{~s}$.

Even though these analyses provide some assurance regarding the time required to obtain homogeneity, our goal was to accumulate a data set that we could use to compute summary statistics and so establish a standard for all tanks. We, therefore, completed some further analysis of the data based on the following rationale.

The question with respect to individual tanks is: how long does a bulk tank have to be agitated to ensure that composition analysis errors due to mixing are minimized? To answer that question, mixing errors must be isolated from sampling and analytical errors. In this particular case, differences between samples due to sampling and handling should be negligible because the samples were taken at 10 -s intervals with a mechanical sampling device, and the samples were held at near $1^{\circ} \mathrm{C}$ until they were analyzed. One could envisage a distorted composition analysis due to a clump of churned fat or perhaps a large cluster of globules on the milk surface. However, this would be properly described as a mixing error, although the impact would be larger for top-sampling in the event that churned fat or fat globule clusters were included in the sample. So, we concluded that sampling error effects could 
Table 3. Statistical summaries of mixing times (s) as determined by: Experiment A with 26 tanks tested by bottom-sampling after $3 \mathrm{~h}$ of creaming; and experiment B with 5 tanks of varying shapes tested 5 times after $1 \mathrm{~h}$ of creaming. CL = Confidence limits. The upper 95 and 99\% CL for $\mathrm{x}$, that is, an individual observation, are estimated as the mean plus 2 and 3 standard deviations, respectively.

\begin{tabular}{lccc}
\hline & & \multicolumn{2}{c}{ Experiment B } \\
\cline { 3 - 4 } & Experiment A & Bottom-sampling & Top-sampling \\
\hline Total observations & 26 & 25 & 25 \\
Creaming time (h) & 3 & 1 & 1 \\
Mean mixing time & 56.5 & 20 & 34 \\
Standard deviation & 21.2 & 8.8 & 10 \\
Upper 95\% CL for mean $(\mu)$ & 65.1 & 23.7 & 38.1 \\
Lower 95\% CL for mean $(\mu)$ & 48 & 16.3 & 29.9 \\
Upper 95\% CL for $x$ & 98.9 & 37.6 & 64 \\
Upper 99\% CL for $x$ & 120.1 & 46.4 & 64 \\
\hline
\end{tabular}

safely be excluded from our analysis of mixing errors, particularly for bottom-sampling experiments. That leaves only analytical errors to consider.

Analytical errors are evaluated in several ways as part of the quality control (QC) program in the milktesting laboratory of Laboratory Services Division, University of Guelph, where our samples were tested. The $\mathrm{QC}$ test that seemed most relevant to our purpose is a test that monitors repeatability of the infrared milk analyzers using control milks. Control milk samples are subsampled from a large batch of UHT-treated milk that can be preserved for several months. Control milks are tested on an hourly basis at LSD and the accumulated data can be used to estimate instrument repeatability over time. The overall standard deviation of differences between instrument estimates and control milk chemical values for 2001 was $0.0215 \%$, wt/vol, which in relation to $3.8 \%, \mathrm{wt} / \mathrm{vol}$, the average fat content of Ontario milk (DFO, 2002), can be interpreted as a variation of about $\pm 0.5 \%, \mathrm{wt} / \mathrm{wt}$. This percentage corresponds to \pm 0.005 on the normalized fat curves computed in this study.

When applied as a control limit to the data for the 26 tanks (Figure 4), the statistical summary indicates that the mean, standard deviation, minimum, and maximum times to obtain a homogenous sample were 56.5, 21.2, 30 and $110 \mathrm{~s}$, respectively. The lower and upper 95\% control limits for the sample mean were 48.0 and $65.1 \mathrm{~s}$, respectively. These data are summarized in Table 3, which also indicates that 95 and $99 \%$ confidence limits for individual estimates of mixing time are 99 and $120 \mathrm{~s}$, respectively. We, therefore, predict that agitation for 2 min would be inadequate about $1 \%$ of the time. Considering the financial impact of inaccurate testing, this is probably not good enough for many jurisdictions, but it must be noted that mixing times for the 26 tanks were measured after $3 \mathrm{~h}$ of creaming, and we know from the literature and from our own bench top and field creaming experiments that the onset of cream- ing requires 40 to 50 min (Figure 3). Accordingly, we conducted further experiments to evaluate mixing time after 60 min of creaming.

\section{Top vs. Bottom-Sampling}

The average normalized fat content versus mixing time for both bottom and top-sampling data for 5 replicates of one tank are plotted in Figure 6. Analysis of variance (ANOVA) of bottom-sampling data indicated significant differences between farms with respect to mixing time, but importantly, the differences were not associated with tank shape. Top-sampling data showed no effects of farm or tank shape. Statistical summaries

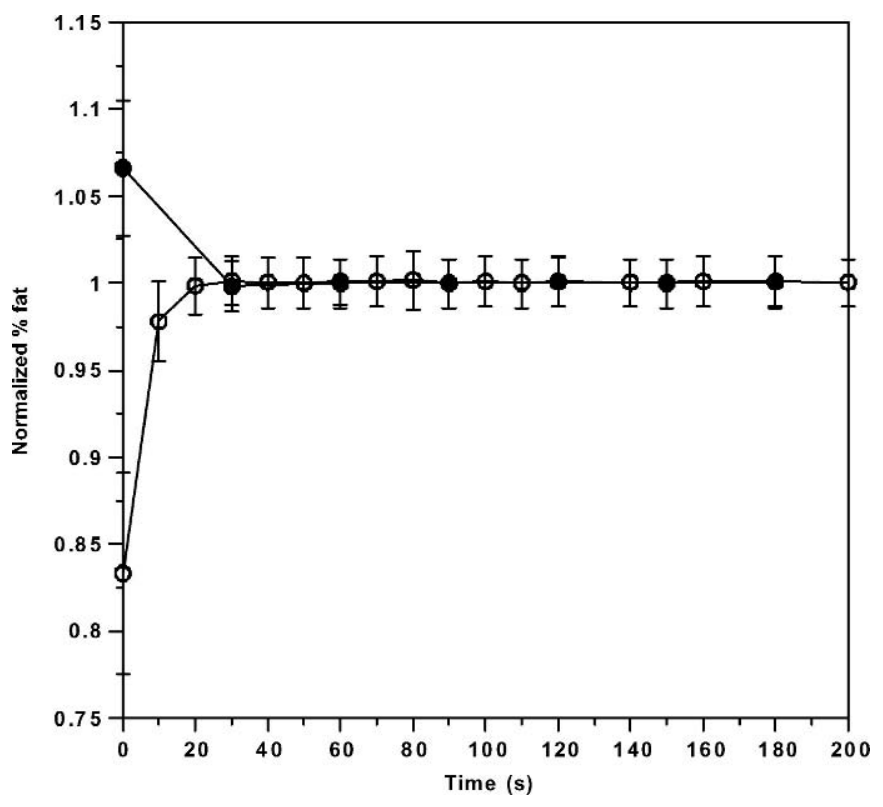

Figure 6. Normalized fat values versus time during mixing following $1 \mathrm{~h}$ of creaming in both top $(-)$ and bottom $(\bigcirc)$ samples. Normalized fat values are decimal fractions of the fat content of the same milks after thorough mixing. The data is from one of 25 trials. 
for mixing times as estimated using both top- and bottom-samples are presented in Table 3.

Several observations are worthy of note. First, bottom-sampling data indicate that mixing time after $1 \mathrm{~h}$ of creaming was much shorter than after $3 \mathrm{~h}$ of creaming. Second, top-sampling results indicate longer mixing times relative to the bottom-sampling data, but this is almost certainly due to fewer data points in the case of top-sampling. The mean mixing time for top-sampling is estimated at $34 \mathrm{~s}$, but at this time, top-sampling would only produce one sample. The fact that the estimated mean is less than $60 \mathrm{~s}$ (2 samples) means that in many cases the milk was fully mixed after $30 \mathrm{~s}$; but if not, any mixing times between 30 and $60 \mathrm{~s}$ would not be detected. So, the net effect is to overestimate the mixing time. Similarly, few data means a larger standard deviation so the confidence limits are wider relative to bottom-sampling. Finally, and most importantly, these results are conclusive evidence that, provided bulk tanks are agitated at hourly intervals, agitation for 2 min before milk sampling is more than adequate to ensure homogenous samples for composition testing.

\section{Mixing Time for Quality Testing}

Bacterial counts were within normal ranges (5 to $40,000 / \mathrm{mL}$ ) and were generally correlated with fat content as expected, given the knowledge that bacteria tend to associate with fat globules (Belknap, 1978). ANOVA did not indicate significant differences between top and bottom-sampling with respect to bacterial counts. However, as illustrated in Figure 7, the counts for bottom-sampling were more variable, so the unequal variance may have influenced the ANOVA analysis. Greater variability for bottom-sampling may be due to contamination associated with the bottom-sampling device or perhaps due to displacement of sediment particles from the bottom of the tank during sampling.

\section{CONCLUSIONS AND RECOMMENDATIONS}

Creaming onset in field experiments occurred after between 40 and 50 min of quiescence. Bottom-sampling data obtained when mixing was instigated after $3 \mathrm{~h}$ of creaming indicate that the mean mixing time required to ensure a homogenous sample for composition testing was $57 \mathrm{~s}$ and the confidence limits predict a $1 \%$ chance that an individual tank would require more than $2 \mathrm{~min}$ of agitation. Bottom and top-sampling data determined when mixing was instigated after $1 \mathrm{~h}$ of creaming indicate mean mixing times of 20 and $34 \mathrm{~s}$, respectively, and confidence limits predict that individual tank mixing times will exceed 46 and $64 \mathrm{~s}$, respectively, less than $1 \%$ of the time. Bacterial cell counts were found to correlate with fat content.

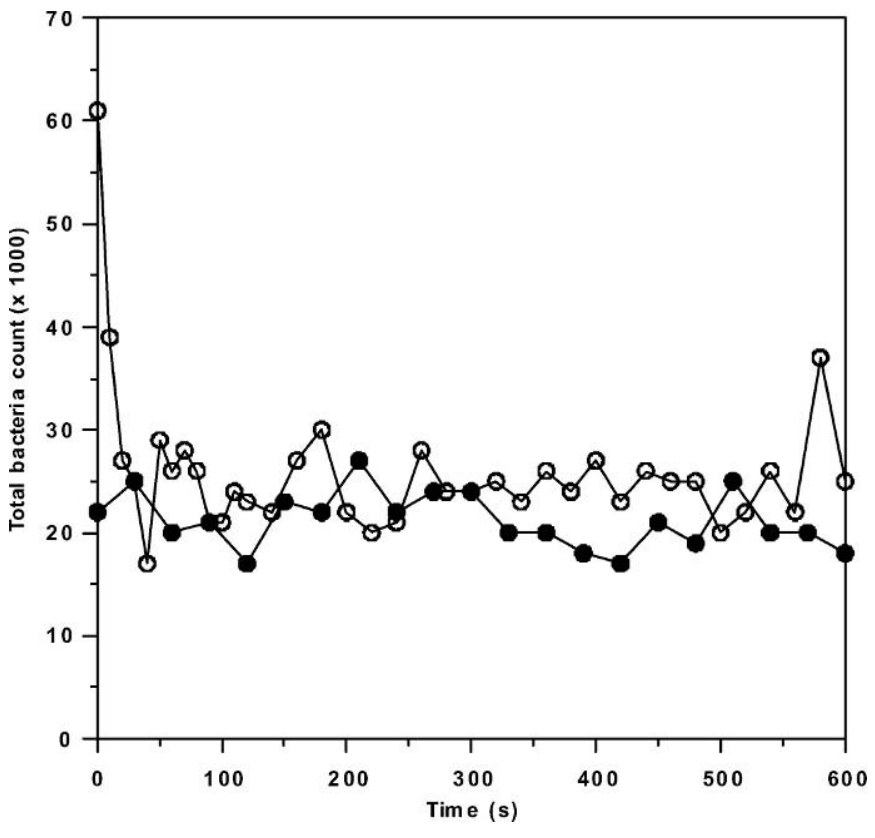

Figure 7. Total bacteria counts, as determined by Bactoscan, versus agitation time for both top $(\bullet)$ and bottom $(\bigcirc)$ samples after 1 $\mathrm{h}$ of creaming. The data are from one of 25 trials.

Based on these results, it is reasonable to recommend that hourly agitation of bulk tanks as currently prescribed in many jurisdictions should be maintained. It would appear that intermittent agitation could be reduced from 5 to $2 \mathrm{~min}$. However, further studies would be necessary to determine whether this agitation time reduction significantly affects the amount of churned fat. Provided that hourly agitation is effected during milk storage, agitation time before sampling could also be reduced from 5 to 2 min without significantly influencing milk sample homogeneity. In fact, 2 min would be conservative, since this degree of mixing was able to achieve homogeneity in milk that had creamed for $3 \mathrm{~h}$, whereas, with intermittent mixing every hour, the degree of creaming would be much less. These recommended protocol revisions will lead to more efficient and cost effective use of both collection trucks and drivers without the risk of impacting fat globule stability.

\section{ACKNOWLEDGMENTS}

Financial assistance and technical support of the Dairy Farmers of Ontario are acknowledged with thanks. We also acknowledge the technical assistance of Paul Spagnuolo.

\section{REFERENCES}

Beauséjour, M. 1992. Flowmeters and sampling equipment on milk collection tankers: Report of Subject B30. International Dairy Federation Bull. No. 279. IDF, Brussels, Belgium. 
Belknap, R. A., W. L. Arledge, K. W. Whaley, E. O. Wright, and A. F. Zimmerman. 1978. Sampling Dairy and Related Products. Pages 33-40 in Standard Methods for the Examination of Dairy Products. E. H. Marth, ed. 14th ed. American Public Health Association, Washington, DC.

Dahlberg, A. C., and J. C. Marquardt. 1931. Pages 2-11 in The Creaming of Raw Milk. New York Bulletins. Cornell University New York State Agricultural Experiment Station, Geneva, Bull. No. 593.

DFO. 2001. Bulk Milk Tank Grader's Manual. Dairy Farmers of Ontario, Mississauga, ON.

DFO. 2002. Dairy Statistical Handbook 2000-2001, 17th ed. Dairy Farmers of Ontario, Mississauga, Ontario, Canada.

Dunkley, W. L., and H. H. Sommer. 1944. Pages 1-56 in The Creaming of Milk. Wisconsin Research Bulletins, Agricultural Experiment Station of the Univ. of Wisconsin, Madison, Bull. No. 151.

Goodridge, L. D., A. Hill, and R. Lencki. 2004. A review of international standards and the scientific literature on farm milk bulk tank sampling protocols. J. Dairy Sci. 87:3099-3104.

Hammer, B. W. 1916. Pages 89-91 in Studies on the Creaming Ability of Milk. Iowa State College of Agriculture and Mechanics Agricultural Experiment Station, Ames, Bull. No. 31.
IAFP. 1994. 3-A Sanitary Standards for Farm Milk Cooling and Holding Tanks, Number 13-09 International Association of Food Protection, United States Public Health Service, The Dairy Industry Committee. Dairy Food Environ. Sanit. 14:106-114.

IDF. 1995. Milk and milk products: Guidance on sampling. International Dairy Federation Standard 50C. Brussels, Belgium.

Jackson, A. C. 1981. Agitation and sampling of tankers and storage tanks. J. Soc. Dairy Technol. 34:98-103.

Ma, Y., and D. M. Barbano 2000. Gravity separation of raw bovine milk: Fat globule size distribution and fat content of milk fractions. J. Dairy Sci. 83:1719-1727.

OMAF. 1983. The Milk Act and Regulations of Ontario. Ontario Ministry of Agriculture and Food, Toronto, Ontario.

SAS Institute. 2000. SAS User's Guide. Statistics. Version 6. SAS Inst., Inc., Cary, NC.

Walstra, P. 1983. Pages 119-133 in Physical Chemistry of Milk Fat Globules. Developments in Dairy Chemistry. Vol. 2. P. E. Fox, ed. Applied Science Publishers, New York, NY.

Walstra, P., T. J. Geurts, A. Noomen, A. Jellema, and M. A. J. S. Van Boekel 1999. Pages $1-26,120-122$ and $182-187$ in Dairy Technology: Principles of Milk Properties and Processes. Marcel Dekker, New York, NY. 